\title{
Schwannomas of Gastrointestinal Tract; a comprehensive review
}

\author{
Heng Siang Ting, BM Yashodhara, Htoo Htoo Kyaw Soe, \\ Uduman Ali Mohamed Yousuf, Jaswant Singh
}

\section{ABSTRACT}

Gastrointestinal Schwannomas (GIS) are neurogenic, spindle cell, mesenchymal tumors, and arise from Schwann cells of myenteric plexus; the cells which form the sheath of the nerves. Schwannomas (SNs) usually arise from spinal roots and peripheral nerves in Schwannomatosis, the third major form of neurofibromatosis, but they are most wellknown to originate from cranial nerves as in vestibular schwannomas. On the contrary, a sporadic Schwannoma which occurs in hollow organs such as the GI tract is remarkably rare. The Gastrointestinal Schwannomas pose a diagnostic \& interventional challenge as it is difficult to differentiate them, peri-operatively or pre-operatively, from more commonly occurring, more malignant, GastrointestinalStromal Tumors (GIST). The exact incidence of gastrointestinal Schwannomas is not known, due to lack of consensus in the nomenclature of these tumors; they are called

Heng Siang Ting ${ }^{1}$, BM Yashodhara², Htoo Htoo Kyaw Soe ${ }^{3}$, Uduman Ali Mohamed Yousuf ${ }^{4}$, Jaswant Singh ${ }^{5}$

Affiliations: ${ }^{1}$ Senior Medical Officer, Department of Surgery, Hospital Sebarang Jaya, Penang, Malaysia; ${ }^{2}$ Professor, Department of Medicine, Melaka Manipal Medical College, Melaka, Malaysia; ${ }^{3}$ Associate Professor, Department of Community Medicine, Melaka Manipal Medical College, Melaka, Malaysia; ${ }^{4}$ Professor \& HOD, Department of Medicine, Melaka Manipal Medical College, Melaka, Malaysia; ${ }^{5}$ Clinical Professor, Department of Medicine, Melaka Manipal Medical College, Melaka, Malaysia.

Corresponding Author: Prof. Dr. BM Yashodhara, Department of General/Internal Medicine, Melaka Manipal Medical College, MAHE, Jalan Batu Hampar, Bukit Baru, Melaka, Malaysia, 75150; Email: bmyashodhara@gmail.com

Received: 12 May 2018

Accepted: 26 July 2018

Published: 20 August 2018 schwannomas, neurinomas, neurilemmomas, neurolemmomas, and Schwann cell tumors. The literature review suggests that they contribute to $1 \%$ gastrointestinal tumors and 2-8\% of gastrointestinal mesenchymal tumors.

Keywords: Comprehensive review, Gastrointestinal schwannomas, Gastrointestinal-Stromal tumors, Gastrointestinal tract, Schwannoma

\section{How to cite this article}

Ting HS, Yashodhara BM, Soe HHK, Yousuf UAM, Singh J. Schwannomas of Gastrointestinal Tract; a comprehensive review. Int $\mathrm{J}$ Case Rep Images 2018;9:100945Z01HT2018.

Article ID: 100945Zo1HT2018

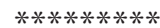

doi: 10.5348/100945Zo1HT2018RA

\section{INTRODUCTION}

The most common tumors of the gastrointestinal (GI) tract are epithelial neoplasia and lymphomas. Each of the intricate \& complex mesenchymal tissue of gastrointestinal tract has the propensity of differentiating into a variety of tumoral lesions, and these are now called Mesenchymal (non-epithelial, stromal) non-gastrointestinal stromal tumors (Non-GIST) of the digestive tract (MNGTDT) after decades of confusions about their nomenclature [1].

There were times when naming these tumors were non-uniform and this created enormous confusions and controversies in defining the histogenesis, pathogenesis, anatomical and clinical features, biological behaviour, pathogeny, classification, and risk stratification, and particularly the management of these pathologies. Assisted by local \& conventional, transcontinental, limited 


\section{EDORIUM Journals}

case-series, sporadic reports and further empowered by the advances in histology, immunohistochemistry, and ultrastructural sciences, researchers Martin (1960), Stout (1962), Mazur and Clark (1983) initiated the subcategorization of these mesenchymal digestive tract tumors, into two main subtypes based on phenotype and biological behavior [1]. The first one is GIST, which are believed to originate from the mesenchymal, pluripotent interstitial cells of Cajal (ICC), [2, 3] pacemaker cells meant for the starting and propagation of gastrointestinal motility. The second less common subgroup, but with a broad lesional-continuum, comprises of tumoral lesions arising from mesodermal tissues similar to those found in the soft parts of the body, i.e. smooth muscle and nervous tissue, as well as fat, fibrous and vascular cellular elements [1]; which could give rise to tumors such as, Lipomas, Leiomyomas, Leiomyosarcomas, Fibromas, Desmoid tumors and Schwannomas.

Schwannomas were first described by Verocay in 1910 [2]. Schwannomas are benign, slow-growing mesenchymal neoplasms and originate from Schwann cells. They are rare tumors, occurring most commonly in acoustic nerves or spinal nerves [3]. The exact incidence of GI schwannomas (SNs) is not known. Review of the literature suggests that soft tissue tumors contribute about $1 \%$ of all gastrointestinal tumors; and schwannomas account for about $2 \%$ to $8 \%$ of all gastrointestinal submucosal tumors [4-7]. The common mesenchymal tumors of GIT are mentioned in Table 1.

SNs are commonly found in the stomach followed by caecum or rectosigmoid junction. The presentation of these tumors depends on the location of these lesions in the GIT. This review article explores more about the GI Schwannomas; their occurrence, presenting features, investigations \& treatment and prognosis of these lesions.

\section{Schwannoma Vs Neurofibromas Vs GI Schwannomas}

A little recap of the anatomy of nervous system helps us better understand these tumors. The Central Nervous System (CNS) consists of the brain, Spinal cord and peripheral nervous system(PNS). The PNS contains nerves all over the body which send faster \& efficient signals to CNS with the help of the myelin sheath covering them. The nerve sheath in PNS originates from Schwann cells and the same myelin in CNS arises from oligodendrocytes. Schwannomas and Neurofibromas are very similar type of benign nerve sheath cell tumors, [8] slow growing with

Table 1: The common mesenchymal tumors of GIT

Gastrointestinal Stromal Tumors (GIST)
Lipomas,
Leiomyomas
Leiomyosarcomas,
Fibromas,
Desmoid Tumors
Schwannomas

very low malignant potential, but with slight differences in diagnosis, treatment and prognosis. Schwannomas arise from myelin sheath producing cells, called Schwann cells and these tumours displace the nerves from which they originate but not encase them. Neurofibromas also arise from the Schwann cells, but they do not displace the nerves from which they arise and rather they just encase them unlike Schwannomas. Cell composition in Schwannomas is mainly one cell type. Neurofibromas like schwannomas arise from Schwann cells; however, may contain other cellular elements like fibroblasts, endothelial cells, and mast cells [5]. Schwannomas and Neurofibromas may occur sporadically [5, 9] or in a genetically transmitted neurological condition called Neurofibromatosis (NF); but they occur in different subtypes of Neurofibromatosis; Schwannomas in NF-2 and Neurofibromas in NF-1. The GI Schwannomas differ from peripheral nerve schwannomas. GI schwannoma differs significantly from soft tissue schwannoma and may be a separate lesion. Surprisingly, GI schwannomas frequently resemble Neurofibromas. Table 2, highlights these differences [10].

\section{History of Neurofibromas and Schwan- nomas, their first references, nomencla- ture and syndromic descriptions}

Even though the discovery of genetic association of these tumors is recent, the earliest non-scientific pictoral or written descriptions or the references to some of the features resembling neurofibromatosis of NF-1 type, can be traced; in the Ebers Papyrus or Ebers Papyrus of 1550 BC - the Egyptian ancient written documents named after the German Egyptologist, Georg Moritz Ebers; and on a Hellinistic statuette in a Greek city of Smyrna a Greek city dating back to antiquity located at a central and strategic point on the Aegean coast of Anatolia of 323 B.C.; and in the coinage of the Parthians kings of

Table 2: Highlights these differences between GI Schwannomas and Soft Tissue Schwannomas

\begin{tabular}{|c|c|}
\hline $\begin{array}{l}\text { GI Schwannoma (GIS) } \\
{[4,11]}\end{array}$ & Soft Tissue Schwannoma \\
\hline $\begin{array}{l}\text { - Prominent lymphoid cuff } \\
{[1,4,11,12,13]}\end{array}$ & - No lymphoid cuff \\
\hline $\begin{array}{l}\text { - Non-encapsulated, well } \\
\text { circumcised [1] }\end{array}$ & - Encapsulated \\
\hline $\begin{array}{l}\text { - Vague palisading at most, } \\
\text { Bipolar spindle cells, cells } \\
\text { with pointed ends, [4] } \\
\text { Absence Antony A and } \\
\text { Antony B areas [13] }\end{array}$ & $\begin{array}{l}\text { Prominent palisading } \\
\text { and Verocay bodies, } \\
\text { absence Antony A and } \\
\text { Antony B areas }\end{array}$ \\
\hline - Lacks hyalinised vessels & $\begin{array}{l}\text { - Frequent hyalinised } \\
\text { vessels }\end{array}$ \\
\hline - Lacks xanthoma cells & - Frequent xanthoma cells \\
\hline - No NF2 mutations & $\begin{array}{l}\text { - } 40-60 \% \text { have NF2 } \\
\text { mutations }\end{array}$ \\
\hline
\end{tabular}




\section{EDORIUM Journals}

247 B.C. $[14,15]$. Neuromas of NF-1 were first discovered by Friedrich Daniel von Recklinghausen in 1882, and he was the first to describe the source of these skin tumors to be nerves and he also coined the name of the disease, neurofibromatosis also called as von Recklinghausen's disease $[14,15]$. Table 3 gives a brief summary of important historical details of neurofibromas and schwannomas, their first nomenclature and syndromic descriptions over the last century.

\section{Do GI Schwannomas occur in NF-1, NF-2 and Schwannomatosis (NF-3)?}

Occurrence of NF-1 is more common than NF-2 and constitutes $97 \%$ all cases neurofibromatosis and has an incidence of 1 in 3500 live births, NF-2 (2-3\%) has an incidence of 1 in 25,000 live births. NF-1 and NF-2 are genetic syndromes, with autosomal dominant mode of inheritance, that lead to tumorous conditions in the body and further evaluation should be based on the symptoms of the patients; if they have bone symptoms the evaluation should focus on osteosarcomas, GI symptoms necessitate investigations for periampullary \& duodenal tumors (GIST tumors, stomatostatinomas). Leimyosarcomas occur less frequently in these conditions. In NF-2 common tumors are bilateral acoustic schwannomas and meningiomas of brain [9].

Davis and Beck estimated that gastrointestinal involvement occurs in 25\% patients with NF-1 [16-18] commonly in jejunum or ileum [16] and in a series analysis of all articles on NF-1 and NF-2 in PubMed \& Medline, it was found that, histologically these tumors commonly are carcinoids (41\%), Neurofibromas (30\%), Neurfibrosarcomas (8\%) and a GI adenocarcinomas (8\%) or even GISTs [9]. Malignant transformation of GI tumors in NF-1 patients is higher than in the general population and is estimated to be 2-5\% [19]. GI Schwannomas occur rarely in NF-2 but not reported in NF-3 [9, 20]. The other

Table 3: Gives a brief summary of important Historical details of Neurofibromas and Schwannomas, their first nomenclature and syndromic descriptions over the last century [14, 15]

- Robert William Smith in 1849: The first systematic review on these NF tumors:

- Van der Hoeve (1921), Yakovlev and Guthrie (1931), and Van Bogaert (1935): described the skin features of NF-1 as neurocutaneous syndromes and phacomatosis.

- Eduard Sandifort in 1777 AD: The first known mention of an acoustic neuroma

- John H. Wishart: gave the first account of bilateral acoustic neuroma in 1822; after an autopsy, on a 21 year old dead man who had the disease from his childhood.

- Older, Virchow, von Recklinghausen, and Verocay: first classified "neuromas"

- Masson \& Penfield first used the word: "schwannoma".

- In 1903 Henneberg and Koch described: NF2 in detail.

- Young, Eldridge, and Gardner, in the late '70: established NF2 as a distinct familial entity. genetic syndrome associated with GI Schwannomas is Carney's complex [2]. On review of available literature, sporadic cases of GI Schwannoma and unilateral vestibular schwannoma have been reported; the patent had intussusception as the presenting symptom due to GI schwannoma in descending colon and it occurred many years after a surgical removal of unilateral Vestibular Schwannoma [7] Apart from NF-1 and NF2, a third distinct genetic syndrome has been identified called as Schwannomatosis (NF-3) which is very rare and is characterized by multiple schwannomas without the common presentations of NF-1 and NF-2 [21]. The schwannomas in these patients are distributed in cranial, spinal and peripheral nerves but vestibular schwannomas are not seen like in NF-2 [21]. There are a few varied criteria for making the diagnosis of NF-3 but the one which is easy to follow is that any patient older than 30 years with two or more non-intradermal schwannomas and who has no vestibular schwannomas on MRI Contrast and lacks genetic mutations of NF-2, and has a first degree relative (s) with confirmed Schwannomatosis, is diagnosed have $\mathrm{NF}-3[21]$.

\section{GI Schwannomas (GIS)}

Since Verocay first described Schwannomas in 1910, $[4,22]$ and Daimaru first reported GIS in 1988, [4] they are increasingly being diagnosed with the recent advances in diagnostic technology and immunohistochemistry [4, 22]. They do occur sporadically but not that commonly with NFs $[20,22,23]$. These tumors can arise in any part of the GI tract from esophagus to colon and rectum, [4, $11,17]$ and rarely in the small intestine $[17,24,25] .70 \%$ GIS occur in the stomach [20]. These slow growing soft tissue, spindle cell tumors constitute $1 \%$ of GI tumors, $[4,22] 0.2 \%$ of all gastric tumors, $[13,17]$ and $2-8 \%$ of GI mesenchymal tumors [4, 13, 22-25]. In comparison, the most common, the other GI spindle cell mesenchymal tumor GIST, occurs 50-100 times more commonly than GIS [11] and constitutes 80\% GI mesenchymal tumors [13] Albeit both these spindle cell mesenchymal tumors may have similar clinical presentation and features of resemblance on endoscopy or colonoscopy, they need to be differentiated early from each other pre, peri or postoperatively as they run altogether different course in connection with complications, treatment and prognosis with GIST tumors being more malignant than GIS. Only a few case reports on a review of the literature [26, 27] mention malignant nature of GIS; 8 in GI hollow viscera, 4 in pancreas [27] and a few in the small intestine [19, 25, $28,29]$.

\section{Presentation of GI Schwannomas}

The commonest sites of occurrence of these polypoidal intraluminal lesions [4] are stomach, [1, 7] colon, caecum [4] rectum, [30] and rare in ascending colon [26] esophagus, and rarely in jejunum [31]. GIS that are large enough can cause luminal obstruction of GIT $[4,6,13]$. 


\section{EDORIUM Journals}

Other symptoms also depend on the location of these tumors in GI. Schwannomas in esophagus [13, 24, 32] can present with dysphagia [7, 9] and those originating from small intestine can present with fatigue, anemia, [8] intussusception, and mass abdomen [9, 13, 33]. Sometimes these tumors are picked up coincidentally [32] during routine endoscopic screening [34] or by endoscopic evaluations prompted by changes in bowel habits, abdominal pain, [13] GI bleeding, [4, 13, 14] difficulty in defecation $[1,9]$ or positive occult blood tests performed during colorectal screening $[23,35]$. When they occur in stomach, the commonest site of these tumors, they are usually asymptomatic $[36,37]$ and in the subset of symptomatic patients, presentation due to bleeding as the first symptom is seen in $14 \%$ cases; and this usually in the form of melena and rarely as hematemesis [36]. Other presentations of GIS in stomach, include epigastric pain persisting for many months, [37] vomiting, weight loss, perforation, with abscess formation, and rarely pleural effusion [13]. The presentation of malignant GIS is similar to non-malignant GIS [19].

\section{Age of Presentation of GI Schwannomas}

Unlike the Vestibular intra-cranial schwannomas in NF-2 which present in early childhood or late adolescence, [38] age of occurrence of GIS varies from 18-87 years, but commonly in 6th to 7 th decade of life [39] and equal in incidence in both genders, [4, 22, 26] however some of the literature, reports a decade earlier $[10,17,31]$ median-age of incidence GIS with a female preponderance $[10,13,17]$. Schwannomas vary in size from $0.5 \mathrm{~cm}$ with a median tumor-size of $52 \mathrm{~mm}$, [31] to $15 \mathrm{~cm}$ in hollow visceral organs of GI, $[1,10,36]$ while 2

Table 4: Differential Diagnosis of GI Schwannomas \& their Immunohistochemistry [2, 10, 13, 20, 22, 27, 39, 42, 43]

\begin{tabular}{|c|c|c|c|c|c|c|c|c|c|}
\hline & GIS & GIST & GANT & $\begin{array}{l}\text { Neuro- } \\
\text { fibromas }\end{array}$ & $\begin{array}{l}\text { Ganglio- } \\
\text { neuroma }\end{array}$ & $\begin{array}{c}\text { Intestinal } \\
\text { Peri- } \\
\text { neurinoma }\end{array}$ & Leiomyoma & $\begin{array}{l}\text { Leiomyobla- } \\
\text { stoma }\end{array}$ & $\begin{array}{l}\text { Leiomyo- } \\
\text { sarcoma }\end{array}$ \\
\hline S-100 & +++ & - & - & + or ++ & +++ & & - & - & - \\
\hline Vimentin & +++ & - & - & + or ++ & - & ++ & ++ & ++ & $++[44]$ \\
\hline GFAP & + & - & & - & & & - & & \\
\hline $\begin{array}{l}\text { Neuron Specific } \\
\text { Enolase }\end{array}$ & + or ++ & - & - & ++ & +++ & & - & - & - \\
\hline CD $117[2,3,44]$ & - & ++ & ++ & & & & - & & - \\
\hline CD 34 & - & ++ & ++ & ++ & & ++ & - & & ++ \\
\hline Claudin -1 & - & - & & & & ++ & - & - & - \\
\hline CD 56 & +++ & - & & - & +++ & ++ & - & -- & - \\
\hline $\mathrm{C}-\mathrm{KIT}[2,3,44]$ & & +++ & & & & & & & \\
\hline PDGFRA [2, 44] & & +++ & & & & & & & \\
\hline $\begin{array}{l}\text { DOG -1 Mutations } \\
{[2,44]}\end{array}$ & & +++ & & & & & & & \\
\hline SMA & & & & & & & +++ & +++ & +++ \\
\hline Desmin [4] & & & & & & & - & - & ++ \\
\hline PCNA & & & & & & & + & ++ & +++ \\
\hline Synaptophysin & - & & & & +++ & & & & \\
\hline Chromogranin & - & & & & +++ & & & & \\
\hline CD 68 & +++ & & & - & + to +++ & & & & \\
\hline $\begin{array}{l}\text { Actin, } \\
\text { Cytokeratin }\end{array}$ & - & ++ & ++ & . & - & & & & \\
\hline \multicolumn{10}{|l|}{$\begin{array}{l}\text { Syndromic } \\
\text { Associations }\end{array}$} \\
\hline NF -1 & & & & + & + & & & & \\
\hline NF -2 & + & & & & & & & & \\
\hline \multicolumn{10}{|l|}{ NF -3 } \\
\hline $\begin{array}{l}\text { Carney's } \\
\text { Complex }\end{array}$ & + & & & & & & & & \\
\hline
\end{tabular}

Platelet derived growth factor receptor alpha PDGFRA; Smooth Muscle Antigen (SMA); Proliferating Cell Nuclear Antigen (PCNA). 


\section{EDORIUM Journals}

$-4 \mathrm{~cm}$ in intracranial location, [38] $1.5 \mathrm{~cm}$ to $20 \mathrm{~cm}$ in pancreas [27]. The mass of the tumors varies from 1-2 gm to $3000 \mathrm{gm}[1,26]$. Tumor size above $5 \mathrm{~cm}$ in GI tract is considered to be high risk for potential complications and hence needs a curative resection and if not resected, tendency to become malignant is high $[29,39]$.

\section{Investigations}

GI schwannomas are difficult to diagnose preoperatively, [7] although not impossible, [31] as radiological and endoscopic findings are non-specific, not pathognomonic and they masquerade as other common tumors of the bowel [10,33]. A limited information about these tumors can be obtained by Endoscopic evaluations, CT Scans, MRI scans [13] and tumor markers [31, 33]. Histopathology of the resected specimen and aided by immunohistochemistry is the gold standard in the diagnosis of GI Schwannomas [40] GIS during the endoluminal examination appear as bulging masses due to their location in submucosa or muscularispropria [20] may resemble other submucosal lesions, but may be more hard, superficially ulcerated, [4, 13, 36, 40] solid or calcified; [4] Due to these characteristics it is difficult to biopsy these lesions \& to obtain adequate tissue for histopathological diagnosis pre-operatively. EUS has a role in detecting these hypoechoic lesions- [13] with marginal halos \& no internal echoes, [13']- as it identifies their layer of origin [13]. Moreover it also aids in directed biopsy which improves the chances of pre-operative diagnosis by $10 \%$. Inaddition, EUS helps in the detection of irregular margins, surrounding lymph nodes, and cystic spaces in the lesion; the features suggesting malignant transformation [4]. GIS on Barium examination appears as a medium to large contrast deficit [13]. In CT scan and MRI images GIS appear as encapsulated lesions arising from the submucosa and look as homogeneous attenuated masses [4, 13, 26] before and after intravenous contrast $[12,13]$ a feature that can help differentiate them from GISTs which appear heterogeneous due to cystic changes, hemorrhage or necrosis $[12,13]$. Due to their high avidity for fluorodeoxy D-glucose uptake on PET scan GIS façade as other malignant stromal tumors and hence PET scan is of little diagnostic value [4, 13]. Paradoxically, this peculiar behavior of GIS on PET scan could be used as a diagnostic tool and GIS should be suspected if a glowing submucosal lesion is picked up on PET scan [13]. SNs appear hypointense on T1-weighted MRI image and hyperintense on T2 weighted MRI image relative to the muscle $[1,12,13,27]$. Once these sequence of investigations are done, surgical resection, histopathology and immunohistochemistry have to be done to confirm the diagnosis of GIS. The resected specimen appears well-circumcised, non-encapsulated, solitary, round or oval [1] yellowish-white lesions [22]. When subjected to histopathology, it typically shows rich cellular tissue consisting of spindle cells with palisading nuclei, [4, 11] and a lymphoid cuff [4]. Table 2, vide supra, mentions the commonly found histopathological features of GIS.

\section{Immunohistochemistry (IHC)}

Sarlomo-Rikala [41] and Christopher [41] were the pioneers who used immunohistochemistry to differentiate SNs from other GI mesenchymal tumors [41] Leiomyoma and Leimyosarcomas which originate from the smooth muscle, muscularis mucosa and even the smooth muscle of small vessels digestive wall [1] are positive for desmin and smooth muscle actin; GISTs are positive for CD34, CD117 [41]. GIS is typically positive for S-100, [4, 13, 41] Vimentin [4, 41] and unlike peripheral soft-tissue SNs are positive for Glial Fibrillary Acidic Protein (GFAP); GIS is negative for C117, CD34, actins, SMA, Desmin, c-KIT and Cytokeratins. $[4,13,22]$ Table $4[2,10,13,20,22$, $27,39,42,43,44]$, mentions the immunohistochemistry features of GIS, GISTs and other tumors. Malignant GIS are positive for GFAP, Vimentin and Neuron specific enolase (NSE), CD68 and negative for CD117, CD 99, CD34, CD20, S-100, Desmin and SMA [19].

\section{Microscopy and the role of frozen section biopsy}

Schwannomas and GIST on routine microscopic examination show spindle cells. The GIS has prominent cuff $[1,4,11-13]$. The arrangement of the spindle cells in schwannomas is pathognomonic and is called a Verocoy body. The nuclei inside the cells in Schwannomas are slender and ovoid with pointed ends. The tip of the spindle cells have neurofibrillary elements. In hypercellular areas on Haematoxyllin \& Eosin (H\&E) stains, spindle cells have palisading appearance due to alignment of nuclei of these spindle cells in a line or a row. The alternating patterns of palisading blue nuclei interspersed or stacked between pink neurofibrillary stroma, on microscopy in Hemotoxyllin and Eosin staining, are called Verocay bodies; named after Verocay, who first described these in schwannomas. The hypercelluar areas of schwannomas with verocay bodies on H\&E are called Antony A areas, while Antony $B$ areas have more diffuse arrangement of spindle cells with more stroma and myxoid tissue [4, 13], as detailed in Table 2.

The definitive diagnosis of Schwannomas is done by paraffin section which allows visualization of all the microscopic details, while frozen section only shows spindle cells [45] and hence, missing the other vital details as described above and so, it does not help in differentiating between GIST and Schwannoma [46].

\section{Treatment}

Size and location of these tumors and their relation to surrounding structures determine the type of operation [13]. Wedge resection, partial or subtotal gastrectomy, elective laparoscopic gastrectomy, [37] 


\section{EDORIUM Journals}

could be done for SNs in stomach [13, 41]. Endoscopic resection [34], laparoscopic hemicolectomy, [47] and endoscopic-laparoscopic resections, [36] Endoscopic mucosal resection (EMR) [34], are treatment options for tumors arising from other parts of GIT. Complete surgical resection with tumor-free margins is the curative treatment of choice for GI Schwannomas, in general, irrespective of their location [7, 37].

Malignant GIS is treated by all three accepted oncological interventions - surgically by resection, radiotherapy and chemotherapy-all applied together or individually and this decision is on an individual case basis [19].

\section{Prognosis}

These tumors are generally benign and slow growing and hence have an excellent prognosis $[6,13,41]$. In a case series of intra-abdominal Schwannomas, the patients were disease free for a year in one study [13] and asymptomatic for a median follow up of 22 months after the curative resection (range 1-120 months) in another study [31]. In case of malignant transformation, the response to chemotherapy and radiotherapy remains uncertain [7]. Unlike GI adenocarcinomas, these mesenchymal tumors, including GIST, have a lower tendency to metastases to regional lymph nodes or distant organs [13]. Malignant GIS have a poor prognosis as suggested by a series analysis showing that only 4 out 29 patients survived at five years [19].

\section{CONCLUSION}

GIS are not very common tumors and it is not easy to identify them, but in patients with syndromic presentations or in sporadic cases, the diagnosis could easily be made if EUS, PET scan, biopsy and IHC are utilized as tools to confirm the diagnosis.

\section{REFERENCES}

1. Diaconescu MR, Diaconescu S. Mesenchymal (nonepithelial) "non-GIST" tumors of the digestive tract. Chirurgia (Bucur) 2012 Nov-Dec;107(6):742-50.

2. Oppelt PJ, Hirbe AC, Van Tine BA. Gastrointestinal stromal tumors (GISTs): Point mutations matter in management, a review. J Gastrointest Oncol 2017 Jun;8(3):466-73.

3. Abraham SC. Distinguishing gastrointestinal stromal tumors from their mimics: An update. Adv Anat Pathol 2007 May;14(3):178-88.

4. Kanneganti K, Patel H, Niazi M, Kumbum K, Balar B. Cecal schwannoma: A rare cause of gastrointestinal bleeding in a young woman with review of literature. Gastroenterol Res Pract 2011;2011:142781.

5. Das Gupta TK, Brasfield RD, Strong EW, Hajdu SI. Benign solitary Schwannomas (neurilemomas). Cancer 1969 Aug;24(2):355-66.
6. Samarakoon L, Weerasekera A, Sanjeewa R, Kollure S. Giant presacral schwannoma presenting with constipation: A case report. J Med Case Rep 2012 Sep 10;6:285.

7. Jung EJ, Han HS, Koh YC, et al. Metachronous schwannomain the colon with vestibular schwannoma. Ann Surg Treat Res 2014 Sep;87(3):161-5.

8. Wu YL, Chang CY, Hsu SS, et al. Intraspinal tumors: Analysis of 184 patients treated surgically. J Chin Med Assoc 2014 Dec;77(12):626-9.

9. Kresak JL, Walsh M. Neurofibromatosis: A review of NF1, NF2, and schwannomatosis. J Pediatr Genet 2016 Jun;5(2):98-104. doi: 10.1055/s-0036-1579766

10. Aktekin A, Özkara S, Meriç K, Günay Gürleyik M, Aker F, Saglam A. Plexiform schwannoma of the duodenum accompanying pyloric stenosis: Report of a case. Turk J Gastroenterol 2012 Aug;23(4):385-9.

11. George V, Velazco L, Munshi IA, et al. Cecum schwannoma: Uncommon colonic mass and new surgical approach using single site laparoscopy. Case Reports Clin Med 2014;3(3):181-5.

12. Tan AC, Tan CH, C L N, Ng CY. Multimodality imaging features of rectal schwannoma. Ann Acad Med Singapore 2012 Oct;41(10):476-8.

13. Atmatzidis S, Chatzimavroudis G, Dragoumis D, Tsiaousis P, Patsas A, Atmatzidis K. Gastric schwannoma: A case report and literature review. Hippokratia $2012 \mathrm{Jul} ; 16(3): 280-2$.

14. Brosius S. A history of von Recklinghausen's NF1. J Hist Neurosci 2010 Oct;19(4):333-48.

15. Ruggieri M, Praticò AD, Caltabiano R, Polizzi A. Early history of the different forms of neurofibromatosis from ancient Egypt to the British Empire and beyond: First descriptions, medical curiosities, misconceptions, landmarks, and the persons behind the syndromes. Am J Med Genet A 2018 Mar;176(3):515-50.

16. Hahn JS, Chung JB, Han SH, et al. Intestinal neurofibromatosis in von Recklinghausen's disease: Presenting as chronic anemia due to recurrent intestinal hemorrhage. Korean J Intern Med 1992 Jul;7(2):137-42.

17. Rastogi R. Intra-abdominal manifestations of von Recklinghausen's neurofibromatosis. Saudi J Gastroenterol 2008 Apr;14(2):80-2.

18. Chelimilla H, Chandrala CK, Niazi M, Kumbum K. Incidental finding of isolated colonic neurofibroma. Case Rep Gastroenterol 2013 Sep 5;7(3):369-75.

19. Tomica D, Danolic D, Puljiz M, et al. Aggressive intestinal schwannoma malignum mimicking gynecological pathology - A case report. Coll Antropol 2011 Jan;35 Suppl 1:339-43.

20. Hechtman JF, Harpaz N. Neurogenic polyps of the gastrointestinal tract: A clinicopathologic review with emphasis on differential diagnosis and syndromic associations. Arch Pathol Lab Med 2015 Jan;139(1):133-9.

21. Landi A, Dugoni DE, Marotta N, Mancarella C, Delfini R. Spinal schwannomatosis in the absence of neurofibromatosis: A very rare condition. Int J Surg Case Rep 2011;2(3):36-9.

22. Wang WB, Chen WB, Lin JJ, Xu JH, Wang JH, Sheng QS.Schwannoma of the colon: A case report and review of the literature. Oncol Lett 2016 Apr;11(4):2580-2. 


\section{EDORIUM Journals}

23. Leonard A, McCarthy LP, Pastor DM. When a polyp is not a polyp: Incidental finding of a sigmoid schwannoma at first colonoscopic screening. BMJ Case Rep 2018 Feb 17;2018.

24. Gu MJ, Choi JH. Microcystic/reticular schwannoma of the esophagus: The first case report and a diagnostic pitfall. BMC Gastroenterol 2014 Nov 18;14:193.

25. Eskelinen M, Pasanen P, Kosma VM, Alhava E. Primary malignant schwannoma of the small bowel. Ann Chir Gynaecol 1992;81(3):326-8.

26. Ersoy O, Sekmen U, Goksel S, Hamzaoglu H, Paksoy M. Schwannoma in ascending colon: A rare cause of abdominal pain. Case Reports Clin Med 2014;3(5):314-8.

27. Bui TD, Nguyen T, Huerta $S, G u$ M, Hsiang D. Pancreatic schwannoma. A case report and review of the literature. JOP 2004 Nov 10;5(6):520-6.

28. Hirasaki S, Kanzaki H, Fujita K, et al. Ileal schwannoma developing into ileocolic intussusception. World $\mathrm{J}$ Gastroenterol 2008 Jan 28;14(4):638-40.

29. Gaujoux-Viala C, Cervera $\mathrm{P}$, Lepeule $\mathrm{R}$, et al. Schwannoma of the duodenojejunal angle. [Article in French]. Rev Med Interne 2008 Jan;29(1):68-70.

30. Inagawa S, Hori M, Shimazaki J, et al. Solitary schwannoma of the colon: Report of two cases. Surg Today 2001;31(9):833-8.

31. Goh BK, Chow PK, Kesavan S, et al. Intraabdominal schwannomas: A single institution experience. J Gastrointest Surg 2008 Apr;12(4):756-60.

32. Iwata Y, Tanaka C, Komori S, et al. Lobulated esophageal schwannoma resected with concurrent approach from the thorax and cervix. World J Surg Oncol 2018 Feb 13;16(1):29.

33. Tahir TM, Anwar S, Naseem N, Mansoor-Ul-Haq H, Saqib M. Gastric schwannoma in a female patient with pulmonary tuberculosis - a clinicopathological assessment and diagnosis. Malays J Med Sci 2010 Apr;17(2):45-50.

34. Ramai D, Lai J, Changela K, Reddy M, Shahzad G. Transverse colon schwannoma treated by endoscopic mucosal resection: A case report. Mol Clin Oncol 2017 Nov;7(5):830-2.

35. Zhang K, Qu S, Li J, Cheng Y, Shi J, Liu T. A case report of rectal schwannoma treated with laparoscopic proctectomy. Medicine (Baltimore) 2018 Feb;97(7):e9866.

36. Lyros O, Schickel S, Schierle K, Hoffmeister A, Gockel I. Gastric schwannoma: Rare differenzial diagnosis of acute upper gastrointestinal (GI) bleeding. [Article in German]. Z Gastroenterol 2017 Aug;55(8):761-5.

37. Romdhane H, Cheikh M, Mzoughi Z, Slama SB, Ennaifer R, Belhadj N. Gastric Schwannoma: A case report. Clin Pract 2016 Nov 30;6(4):849.

38. Tsao MN, Sahgal A, Xu W, et al. Stereotactic radiosurgery for vestibular schwannoma: International stereotactic radiosurgery society (ISRS) practice guideline. J Radiosurg SBRT 2017;5(1):5-24.

39. Fotiadis CI, Kouerinis IA, Papandreou I, Zografos GC, Agapitos G. Sigmoid schwannoma: A rare case. World J Gastroenterol 2005 Aug 28;11(32):5079-81.

40. Lee NJ, Hruban RH, Fishman EK. Abdominal schwannomas: Review of imaging findings and pathology. Abdom Radiol (NY) 2017 Jul;42(7):186470 .
41. Lin CS, Hsu HS, Tsai CH, Li WY, Huang MH. Gastric schwannoma. J Chin Med Assoc 2004 Nov;67(11):583-6.

42. Hornick JL, Fletcher CD. Intestinal perineuriomas. Am J Surg Pathol 2005 Jul;29(7):859-65.

43. Vrettou E, Karkavelas G, Christoforidou B, Meditskou S, Papadimitriou CS. Immunohistochemical phenotyping and PCNA detection in gastrointestinal stromal tumors. Anticancer Res 1995 MayJun;15(3):943-9.

44. Rubin BP. Gastrointestinal stromal tumours: An update. Histopathology 2006 Jan;48(1):83-96.

45. Sreevathsa MR, Pipara G. Gastric schwannoma: A case report and review of literature. Indian $\mathrm{J}$ Surg Oncol 2015 Jun;6(2):123-6.

46. Kozak K, Kowalczyk M, Jesionek-Kupnicka D, Kozak J. Benign intramural schwannoma of the esophagus - case report. Kardiochir Torakochirurgia Pol 2015 Mar;12(1):69-71.

47. Turaihi H, Assam JH, Sorrell M. Ascending colon schwannoma an unusual cause of acute lower gastrointestinal bleeding. S D Med 2017 Jan;70(1):33-

$* * * * * * * * *$

\section{Acknowledgements}

Melaka Manipal Medical College and MAHE

\section{Author Contributions}

Heng Siang Ting - Substantial contributions to conception and design, Acquisition of data, Analysis and interpretation of data, Drafting the article, Revising it critically for important intellectual content, Final approval of the version to be published

BM Yashodhara - Substantial contributions to conception and design, Acquisition of data, Analysis and interpretation of data, Drafting the article, Revising it critically for important intellectual content, Final approval of the version to be published

Htoo Htoo Kyaw Soe - Substantial contributions to conception and design, Drafting the article, Revising it critically for important intellectual content, Final approval of the version to be published

Uduman Ali Mohamed Yousuf - Substantial contributions to conception and design, Drafting the article, Revising it critically for important intellectual content, Final approval of the version to be published Jaswant Singh - Substantial contributions to conception and design, Drafting the article, Revising it critically for important intellectual content, Final approval of the version to be published

\section{Guarantor of Submission}

The corresponding author is the guarantor of submission.

\section{Source of Support}

None. 


\section{EDORiUM Journals}

Int J Case Rep Images 2018;9:100945Z01HT2018.

www.ijcasereportsandimages.com

\section{Consent Statement}

Written informed consent was obtained from the patient for publication of this study.

\section{Conflict of Interest}

Authors declare no conflict of interest.
Ting et al. 8

\section{Copyright}

(C) 2018 Heng Siang Ting et al. This article is distributed under the terms of Creative Commons Attribution License which permits unrestricted use, distribution and reproduction in any medium provided the original author(s) and original publisher are properly credited. Please see the copyright policy on the journal website for more information.
Access full text article on other devices

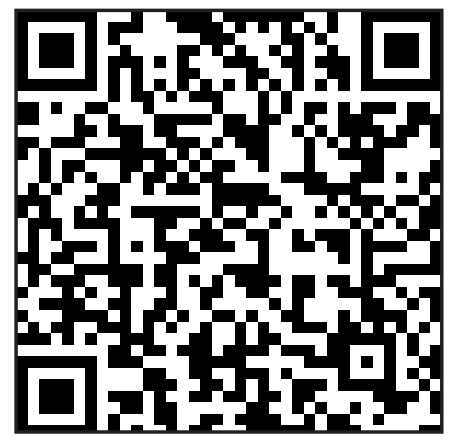

Access PDF of article on other devices

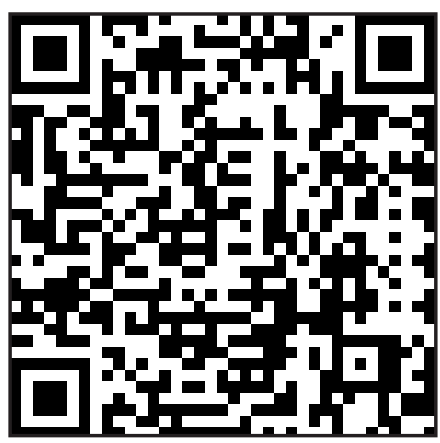

